\title{
Maternal serum inhibin A levels are a marker of a viable trophoblast in incomplete and complete miscarriage
}

\author{
S Luisi, P Florio, D D’Antona ${ }^{1}$, F M Severi, F Sanseverino, S Danero and F Petraglia \\ Chair of Obstetrics and Gynecology, Department of Pediatrics, Obstetrics and Reproductive Medicine, University of Siena, Siena, Italy and \\ ${ }^{1}$ Department of Gynecologic and Human Reproduction Sciences, University of Padova, Padova, Italy \\ (Correspondence should be addressed to Felice Petraglia, Chair of Obstetrics and Gynecology, University of Siena, Policlinico 'Le Scotte', viale Bracci, \\ 53100 Siena, Italy; Email: petraglia@unisi.it)
}

\begin{abstract}
Objective: From early gestation the human trophoblast secretes large amounts of inhibin A and activin A, and their measurement provides a value for predicting the outcome in women who become pregnant after assisted reproductive techniques. The aim of the study was to investigate the putative role of maternal serum inhibin A and activin A levels as markers of a viable trophoblast in women who miscarry.

Design: Controlled cross-sectional study.

Methods: One group consisted of 65 healthy pregnant women (controls), progressing to deliver a healthy singleton baby and another group consisted of 54 miscarriages ( 38 incomplete ( 27 nonviable, 11 anembryonic pregnancies) and 16 complete). Maternal blood samples were collected between 5 and 12 weeks of gestation.

Results: Serum human chorionic gonadotrophin concentrations in women with incomplete or complete miscarriages were significantly (both $P<0.001$ ) lower than in controls; activin A levels being lowest only in women with a complete miscarriage $(P<0.001)$. On the other hand, inhibin A levels were significantly lower in incomplete or complete miscarriage than in controls (both $P<0.0001$ ). Conclusions: Maternal serum inhibin A, but not activin A, determination reflects the lack of a viable trophoblast in complete miscarriage.
\end{abstract}

European Journal of Endocrinology 148 233-236

\section{Introduction}

Inhibin A and activin A are ovarian dimeric glycoproteins composed of disulfide-linked $\alpha$ and $\beta$ a subunits: inhibin $A$ is a $\alpha / \beta A$ heterodimer, while activin $A$ is a $\beta A / \beta A$ homodimer (1). During pregnancy, the human trophoblast (2, 3), fetal membranes (4) and decidua $(5,6)$ express subunit mRNAs and immunoreactive proteins. Significant amounts of both proteins are secreted into the biological fluids of pregnancy (maternal and cord serum, coelomic and amniotic fluids) (7), and the feto-placental unit is the main source of circulating inhibin A and activin A (8). In fact, maternal serum levels of both inhibin $A$ and activin $\mathrm{A}$ are higher than in non-pregnant women and increase during pregnancy (9-13). Multiple donor egg pregnancies have higher concentrations of both proteins compared with singleton donor egg pregnancies (14-16), and maternal circulating concentrations of inhibin A and activin A after the removal of the fetoplacental unit significantly and gradually decrease within the first hour, and decrease to even lower concentrations within the next $3 \mathrm{~h}$ (12). Several studies have attempted to relate the inhibin A measurement with the early pregnancy outcome prediction, some reporting no changes $(10,17)$, and others report low levels and a very rapid decline of inhibin A concentrations in nonviable pregnancy $(15,16)$. However, all these studies evaluated the early pregnancy outcome in women who became pregnant after assisted reproductive techniques, but none in women who were spontaneously pregnant. Furthermore, few data exist on activin A measurement at early gestation in spontaneous pregnancy (15).

On the basis of these findings, patients with incomplete miscarriage (due to non-viable and anembryonic pregnancy) and complete miscarriage were studied, in order to ascertain whether activin A and inhibin A measurements, in comparison with human chorionic gonadotrophin (hCG), might provide a rapid and useful marker of early pregnancy viable placentation.

\section{Materials and methods}

\section{Patients}

Informed written consent was obtained from all patients prior to inclusion in the study for which local Human Investigation Committee approval was obtained. 
Maternal serum was collected from a total of 119 consecutive pregnant women, and 54 of these came to the Division of Obstetrics and Gynecology, Universities of Siena and Padova, with early pregnancy bleeding. Following a positive pregnancy test and serum hCG measurement, ultrasound scans (USS) (Real Time Ultrasound Scan Equipment, Siemens Sonoline ELEGRA, Millennium Edition, Erlangen, Germany, with a transvaginal probe at $4.5-7.0 \mathrm{MHz}$ ) were performed to confirm pregnancy viability.

Pregnant women were thus classified in the following diagnostic groups: (i) Healthy pregnant women (control; $n=65$ ), progressing to deliver a healthy term singleton baby; (ii) incomplete miscarriage $(n=38)$ : USS showed a non-viable embryo (absence of heart beat activity) in 27 patients (non-viable), while there was an anembryonic gestational sac in utero in the remaining (anembryonic; $n=11$ ); (iii) complete miscarriage (miscarriage; $n=16$ ): an empty uterus on USS with a history of the passage of the products of conception.

Blood samples for groups (ii) and (iii) were collected at the time of hospitalization, and when bleeding had occurred at least $12 \mathrm{~h}$ previously. The exclusion criteria were multiple pregnancies, diabetes, hypertension, fetal anomaly, maternal or fetal infection. Chromosomal abnormalities were not found in any of the abortive material collected. In all patients, the gestational age ranged from 5 to 12 weeks of pregnancy (Table 1), as assessed by the last menstrual period and confirmed by USS at hospitalization. At this time, maternal blood was allowed to clot and, after centrifugation, serum was divided into several aliquots and stored at $-80^{\circ} \mathrm{C}$ until assay. All patients had a serum hCG determination in parallel.

\section{hCG assay}

Maternal serum hCG levels were assayed using an IMMULITE analyzer, with a commercial diagnostic kit (EURO/DPC Ltd, Llanberis, Gwynedd, UK). This assay has a sensitivity of $1.1 \mathrm{mIU} / \mathrm{ml}$, and intra- and interassay coefficient of variation $(\mathrm{CV})$ values of $2.1 \%$ and $3.1 \%$ respectively. The assay was highly specific for hCG, with no cross-reactivity with luteinizing hormone, follicle-stimulating hormone and thyrotrophin.

\section{Activin A and inhibin A assay}

Maternal serum activin A and inhibin A concentrations were measured using specific two-site enzyme immunoassays, as previously described (18), and according to the manufacturer's recommendations (Serotec, Oxford, Oxon, UK).

The limit of detection for activin A was less than $100 \mathrm{pg} / \mathrm{ml}$, and intra- and interassay CV values for quality control samples were $<5.0 \%$ and $<7.5 \%$ respectively. The inhibin A detection limit was $4 \mathrm{pg} / \mathrm{ml}$ in serum, and intra- and interassay CVs were $<4.0 \%$ and $<8.0 \%$ respectively. Cross-reactions for each assay with the various inhibin-related proteins were less than $0.5 \%$.

Activin A and inhibin A plates were read at $490 \mathrm{~nm}$ on an automated enzyme-linked immunosorbent assay plate reader (Basic Radim Immunoassay Operator, Radim Spa, Pomezia, Italy).

\section{Data analysis}

Serum hCG $(\mathrm{mIU} / \mathrm{ml})$, activin A $(\mathrm{ng} / \mathrm{ml})$ and inhibin A $(\mathrm{pg} / \mathrm{ml})$ levels were corrected for gestational age by conversion to multiples of median (MoM) of the healthy controls of the same gestational age. The results are expressed as medians and ranges. Differences between groups were assessed by one-way non-parametric

Table 1 Summary of clinical data and values (multiples of median; median and range) of maternal serum activin A, inhibin A and hCG levels in the study population.

\begin{tabular}{|c|c|c|c|c|}
\hline & \multirow[t]{2}{*}{ Healthy controls } & \multicolumn{2}{|c|}{ Incomplete miscarriage } & \multirow[t]{2}{*}{ Complete miscarriage } \\
\hline & & Non-viable & No embryo & \\
\hline \multicolumn{5}{|c|}{ Gestational age (weeks) } \\
\hline $5-6$ & $n=16$ & $n=4$ & $n=2$ & $n=4$ \\
\hline $7-8$ & $n=15$ & $n=15$ & $n=4$ & $n=5$ \\
\hline $9-10$ & $n=17$ & $n=4$ & $n=4$ & $n=4$ \\
\hline $11-12$ & $n=17$ & $n=5$ & $n=1$ & $n=3$ \\
\hline Parity & $1.05 \pm 0.3$ & $1.2 \pm 0.1$ & $1.2 \pm 0.5$ & $1.0 \pm 0.7$ \\
\hline Maternal age (years) & $28.7 \pm 1$ & $27.9 \pm 1$ & $28.6 \pm 2$ & $28.3 \pm 1.4$ \\
\hline $\mathrm{hCG}$ & $\begin{array}{c}1.0 \\
0.13-2.38\end{array}$ & \multicolumn{2}{|c|}{$\begin{array}{c}0.18 \\
0.003-2.85\end{array}$} & $\begin{array}{c}0.005 \\
0.0003-0.02\end{array}$ \\
\hline Activin A & $\begin{array}{c}1.0 \\
0.25-1.61\end{array}$ & \multicolumn{2}{|c|}{$\begin{array}{c}0.86 \\
0.13-2.5\end{array}$} & $\begin{array}{c}0.33 \\
0.12-1.12\end{array}$ \\
\hline Inhibin A & $\begin{array}{c}1.0 \\
0.329-2.53\end{array}$ & & & $\begin{array}{c}0.05 \\
0.006-0.088\end{array}$ \\
\hline
\end{tabular}


analysis of variance (Kruskal-Wallis ANOVA) and post-hoc Dunn's test for multiple comparisons. Between group differences were considered statistically significant whenever $P<0.05$.

\section{Results}

Serum hCG, activin A and inhibin A MoM and median range are shown in Table 1.

Patients with incomplete and complete miscarriage had significantly lower hCG levels than healthy controls (both $P<0.001$ ). In fact, women with complete miscarriage showed the lowest hCG concentrations $(P<$ 0.05) (Fig. 1A). As shown in Fig. 1B, serum activin A levels in healthy controls did not differ compared with incomplete miscarriage. Moreover, serum activin A concentrations did not differ between non-viable and anembryonic pregnancies (data not shown). Patients with complete miscarriage had the lowest levels of activin A, significantly lower than in the other two groups $(P<0.001)$ (Fig. 1B). Serum inhibin A levels were significantly lower in incomplete or complete miscarriage than in healthy controls (both $P<0.001$ ) (Fig. 1C) and those with complete miscarriage showed the lowest inhibin A concentrations, lower than in incomplete miscarriage $(P<0.05)$ (Fig. 1C).

\section{Discussion}

The present study indicates the changes in both serum inhibin A and activin A concentrations in women with incomplete and complete miscarriage; in fact, the study confirmed that inhibin A levels in incomplete miscarriage were significantly lower than in healthy controls, as already reported by Lockwood et al. $(15,16)$. Even though none of the hormones presently evaluated reliably discriminated between the anembryonic (blighted ovum) and the non-viable embryo pregnancy, as already reported (17), the present findings suggest that the production of inhibin A and hCG ceases early in the presence of a failed trophoblast. The evaluation of inhibin A levels, but not of activin A, may therefore be helpful in the management of early pregnancy problems. In addition, the lack of changes in activin A levels between controls and incomplete miscarriage may also be explained by the fact that during the first trimester of pregnancy the ovary may produce activin $A$, as the early pregnancy corpus luteum revealed intense hybridisation with the $\beta$ A subunit in the granulosa cell compartment (19).

In the presence of complete miscarriage, a condition associated with the failure of the trophoblast, maternal serum levels of the three proteins - hCG, activin A, inhibin $\mathrm{A}$ - are the lowest. These data are comparable with those shown in singleton pregnancy after the termination of pregnancy in the first trimester (from 6 to 12 weeks of gestation), when circulating concentrations

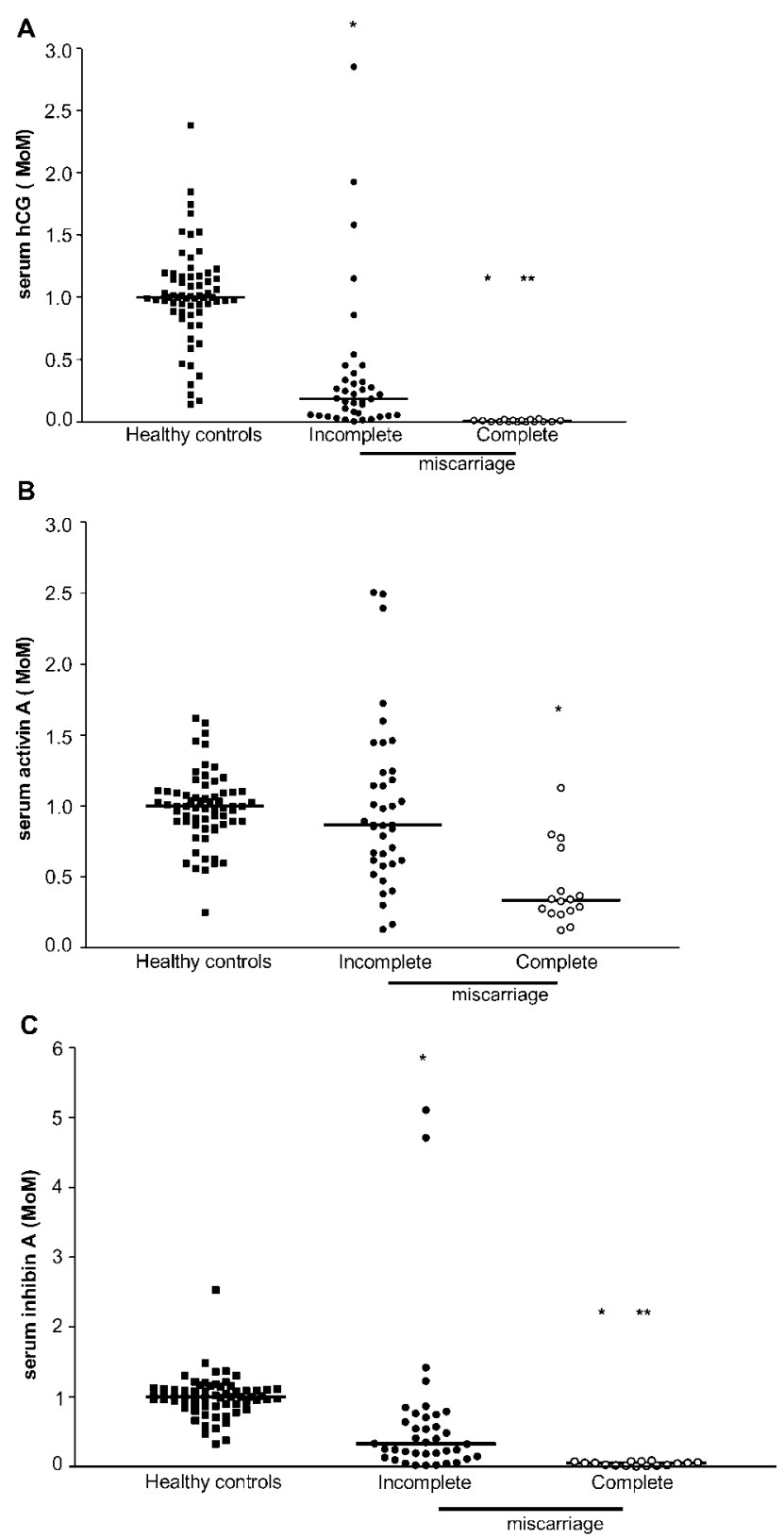

Figure 1 Maternal serum (A) hCG, $(B)$ activin A and $(C)$ inhibin A levels in healthy pregnant women (control), patients with incomplete and complete miscarriage. Individual values are plotted (expressed as MoM) and horizontal bars represent the group medians. $(\mathrm{A}) * P<0.001$ vs healthy controls, ${ }^{*} P P<0.05$ vs incomplete miscarriage; (B) ${ }^{*} P<0.001$ vs healthy controls and incomplete miscarriage; $(\mathrm{C}) * P<0.001$ vs healthy controls ${ }^{*} P<0.05$ vs incomplete miscarriage.

of inhibin A and activin A significantly decrease within the first hour and gradually to even lower concentrations after the removal of the feto-placental unit (12). However, a previous study (10) failed to detect significant inhibin A changes in seven incomplete miscarriages (from 4 to 9 weeks of gestation). This discrepancy may be due to the limited number of 
cases evaluated, but mainly to the fact that inhibin A concentrations were not corrected for gestational age, as serum levels progressively increase from 5 and peak at 9 weeks of gestation $(10-12)$. Thus, when evaluated in a larger population, according to the different gestational ages, or longitudinally in the same patients (12), inhibin A, activin A and hCG levels were found to be significantly lower in patients who miscarry than in healthy patients.

In conclusion, the present findings suggest that inhibin A measurement is more sensitive than activin A determinations in signaling first trimester pregnancy problems, and could be of help in the early prediction of first trimester outcome in pregnant women with incomplete or complete miscarriage.

\section{Acknowledgements}

The present study was supported in part by grants from the University of Siena, Siena, Italy (Piano d'Ateneo per la Ricerca 2001, project entitled: 'Predictive Value of Hormones/Growth Factors Measurements in Feto-maternal Diseases').

\section{References}

1 Vale W, Rivier C, Hsueh A, Campen C, Meunier H, Bicsak T et al. Chemical and biological characterization of the inhibin family of protein hormones. Recent Progress in Hormone Research 198844 $1-34$.

2 Petraglia F, Sawchenko P, Lim AT, Rivier J \& Vale W. Localization, secretion, and action of inhibin in human placenta. Science 1987 237 187-189.

3 Petraglia F, Woodruff TK, Botticelli G, Botticelli A, Genazzani AR, Mayo KE et al. Gonadotropin-releasing hormone, inhibin, and activin in human placenta: evidence for a common cellular localization. Journal of Clinical Endocrinology and Metabolism $1992 \mathbf{7 4}$ 1184-1188.

4 Petraglia F, Anceschi MM, Calza L, Garuti GC, Fusaro P, Giardino L et al. Inhibin and activin in human fetal membranes: evidence for a local effect on prostaglandin release. Journal of Clinical Endocrinology and Metabolism 199377 542-548.

5 Petraglia F, Calza L, Garuti GC, Abrate M, Giardino L, Genazzani AR et al. Presence and synthesis of inhibin subunits in human decidua. Journal of Clinical Endocrinology and Metabolism 1990 71 487-492.

6 Rabinovici J, Goldsmith PC \& Librach CL. Localization and regulation of the activin-A dimer in human placental cells. Journal of Clinical Endocrinology and Metabolism 199275 571-576.

7 Florio P, Cobellis L, Luisi S, Ciarmela P, Severi FM, Bocchi C et al. Changes of inhibins and activin secretion in healthy and pathological pregnancy. Molecular and Cellular Endocrinology $2001180123-130$.

8 Petraglia F, Florio P, Nappi C \& Genazzani AR. Peptide signaling in human placenta and membranes: autocrine, paracrine, and endocrine mechanisms. Endocrine Reviews 199617 156-186.

9 Petraglia F, Garg S, Florio P, Sadick M, Gallinelli A, Wong W-L et al. Activin A and activin B measured in maternal serum, cord blood serum and amniotic fluid during human pregnancy. Endocrine Journal 19931 323-327.

10 Illingworth PJ, Groome NP, Duncan C, Grant V, Tovanabutra S, Baird DT et al. Measurement of circulating inhibin forms during the establishment of pregnancy. Journal of Clinical Endocrinology and Metabolism $1996 \mathbf{8 1} 1471-1475$.

11 Muttukrishna S, Fowler PA, George L, Groome NP \& Knight PG. Changes in peripheral serum levels of total activin A during the human menstrual cycle and pregnancy. Journal of Clinical Endocrinology and Metabolism $1996 \mathbf{8 1} 3328-3334$.

12 Muttukrishna S, Child TJ, Groome NP \& Ledger WL. Source of circulating levels of inhibin A, pro $\alpha$ C-containing inhibins and activin A in early pregnancy. Human Reproduction 199712 1089-1093.

13 Muttukrishna S, North RA, Morris J, Schellenberg JC, Taylor RS, Asselin J et al. Serum inhibin A and activin A are elevated prior to the onset of pre-eclampsia. Human Reproduction $2000 \mathbf{1 5}$ 1640-1645.

14 Birdsall M, Ledger WL, Groome NP, Abdalla H \& Muttukrishna S. Inhibin $\mathrm{A}$ actin $\mathrm{A}$ in the first trimester of human pregnancy. Journal of Clinical Endocrinology and Metabolism $1997 \mathbf{8 2}$ $1557-1560$.

15 Lockwood GM, Ledger WL, Barlow DH, Groome NP \& Muttukrishna S. Measurement of inhibin and activin in early human pregnancy: demonstration of fetoplacental origin and role in prediction of early-pregnancy outcome. Biology of Reproduction 199757 1490-1494.

16 Lockwood GM, Ledger WL, Barlow DH, Groome NP \& Muttukrishna S. Identification of the source of inhibin at the time of conception provides a diagnastic role for them in very early pregnancy. American Journal of Reproductive Immunology $199840303-308$.

17 Treetampinich C, O'Connor AE, MacLachlan V, Groome NP \& de Kretser DM. Maternal serum inhibin A concentrations in early pregnancy after IVF and embryo transfer reflect the corpus luteum contribution and pregnancy outcome. Human Reproduction $2000152028-2032$.

18 Florio P, Luisi S, Viganò P, Busacca M, Fadalti M, Genazzani AR et al. Healthy women and patients with endometriosis show high concentrations of inhibin A, inhibin B, and activin A in peritoneal fluid throughout the menstrual cycle. Human Reproduction $1998132606-2611$.

19 Eramaa M, Heikinheimo K, Tuuri T, Hilden K \& Ritvos O. Inhibin/activin subunit mRNA expression in human granulosaluteal cells. Molecular and Cellular Endocrinology 199392 R15-R20.

Received 26 July 2002

Accepted 4 November 2002 